\title{
The Epsilon Subunit Confers Fast Channel Gating on Multiple Classes of Acetylcholine Receptors
}

\author{
Patricia Camacho, ${ }^{\text {a }}$ Yuan Liu, ${ }^{\mathrm{b}}$ Gail Mandel, and Paul Brehm \\ Department of Neurobiology and Behavior, SUNY at Stony Brook, Stony Brook, New York 11794
}

\begin{abstract}
During vertebrate skeletal muscle development, multiple forms of long-open-time (slow-type) ACh receptor channels are replaced by at least two different types of short-opentime (fast-type) ACh receptors. Expression of ACh receptors in Xenopus oocytes indicates that the substitution of an $\epsilon$ subunit for a $\gamma$ subunit may account for both types of fastgated channel types in adult muscle. Unlike the various forms of the embryonic receptor, in which functional diversity is achieved through alterations in subunit composition, the two major fast-gated forms expressed in oocytes have identical subunit composition. These findings provide a structural basis for both types of short-open-time ACh receptor types found in adult muscle.
\end{abstract}

[Key words: ACh, receptor, oocyte, subunit, patch clamp, development, Xenopus]

At least five functionally distinct nicotinic $\mathrm{ACh}$ receptor channel types coexist in the membrane of skeletal muscle (Brehm, 1989; Steinbach, 1989). On the basis of channel open time, these five channel types can be segregated into three "slow" forms (Owens and Kullberg, 1989a; Salpeter et al., in press) and two "fast" forms (Leonard et al., 1984; Owens and Kullberg, 1989b; Rohrbough and Kidokoro, 1990; Shepherd and Brehm, 1992). Fast channels exhibit channel open times between 1 and $5 \mathrm{msec}$ in mammalian muscle and less than $1 \mathrm{msec}$ in amphibian muscle. In both species the slow channel types have open times that average two to four times longer than the fast channels. The slow and fast forms of the channel are also differentially regulated by nerve; fast channels are characteristic of mature, innervated skeletal muscle (Brehm and Kullberg, 1987), while slow channels are observed in embryonic (Brehm et al., 1984; Siegelbaum et al., 1984; Owens and Kullberg, 1989a), denervated (Henderson et al., 1987), and tonic muscle (Henderson and Brehm, 1989).

Muscle ACh receptor channel types are thought to be formed through the association of five subunits, two $\alpha$, one $\beta$, and one $\delta$ in combination with either $\gamma$ or $\epsilon$ (for review, see Claudio,

\footnotetext{
Received May 7, 1992; revised July 24, 1992; accepted July 31, 1992.

We are grateful to Drs. Paul Gardner for providing the mouse epsilon cDNA, James Boulter for providing mouse $\alpha, \beta, \gamma$, and $\delta$ cDNAs, and Michael White for providing the rat $\epsilon \mathrm{cDNA}$ expression vector. Dr. Richard Goodman provided advice in the cloning of the cDNA encoding the rat $\epsilon$ subunit and Dr. Neil Marrion helped with the analysis of dose-response relations. This research was supported by NIH Grant NS18205 to P.B.

Correspondence should be addressed to Paul Brehm at the above address.

a Present address: Department of Neurosciences, University of Virginia School of Medicine, Charlottesville, VA 22908.

b Present address: Laboratory Devclopmental Ncurobiology, National Institute of Child Health and Human Development, NIH, Bethesda, MD 20892.

Copyright (c) 1993 Society for Neuroscience $0270-6474 / 93 / 130605-09 \$ 05.00 / 0$
}

1989). Several studies have implicated subunit composition in the regulation of receptor function. The expression studies in oocytes and in transfected mammalian cell lines support the idea that the $\epsilon$ subunit confers fast channel function on the receptor while the $\gamma$ subunit confers slow channel function (Mishina et al., 1986; Criado et al., 1990; Gu et al., 1990). However, substituting an $\epsilon$ subunit for a $\gamma$ subunit does not account for all of the functional diversity in channel types. In embryonic muscle for example, functional diversity in slow forms of the receptor may result from omission of either $\gamma$ or $\delta$ subunits (Jackson et al., 1990; Kullberg et al., 1990).

Muscle expresses at least two types of fast channels, a highconductance channel (60-65 pS) that predominates in mature muscle and a lower conductance channel (40-50 pS) that predominates at intermediate stages of development (Leonard et al., 1984; Owens and Kullberg, 1989b; Rohrbough and Kidokoro, 1990; Shepherd and Brehm, 1992). The presence of multiple fast channel forms raises the question of whether substitution of the $\epsilon$ subunit accounts for both types of fast channels and, if so, what other structural differences account for the differences in conductance. We have reexamined the functional consequences of assembling receptors containing $\epsilon$ subunits by expression of ACh receptors in Xenopus oocytes. The present findings indicate that multiple fast forms of receptors are expressed following injection of $\alpha \beta \delta \epsilon \mathrm{CRNAs}$, one type being similar to the fast channel type observed during intermediate stages of development. The observation that $\epsilon$ can account for the full range of fast channel types provides an alternative mechanism to posttranslational modification of a $\gamma$-containing channel type (Carlson and Leonard, 1989).

\section{Materials and Methods}

Complementary RNAs encoding the individual mouse acetylcholine receptor subunits were transcribed, as described previously (Kullberg et al., 1990), from cDNA clones provided by Dr. J. Boulter ( $\alpha \beta \delta \gamma$; Salk Institute) and Dr. P. Gardner ( $\epsilon$; Dartmouth Medical School). A cDNA encoding the rat $\epsilon$ subunit was isolated from a $\lambda$ gt 10 rat skeletal muscle cDNA library (Camacho et al., 1989; Gu et al., 1991). To optimize cRNA production, the rat $\epsilon$ cDNA was subcloned adjacent to $5^{\prime}$ untranslated sequences from the Xenopus 5S rRNA gene in a modified expression vector (O'Leary and White, in press). All synthetic RNAs were injected at a final concentration of $25-50 \mathrm{ng} / \mu \mathrm{l}$ for each subunit, including experiments in which the cRNA encoding the $\beta$ subunit was excluded from the injection mixture.

Oocytes were surgically removed from Xenopus laevis (Nasco) and washed extensively in a solution (OR-3) containing half-strength L-15 medium (GIBCO), $1 \mathrm{~mm}$ glutamine, $200 \mu \mathrm{g} / \mathrm{ml}$ gentamicin, and $15 \mathrm{~mm}$ HEPES (pH 7.6). The oocytes were treated for 20 min with $20 \mathrm{mg} / \mathrm{ml}$ collagenase (GIBCO) dissolved in OR-3 prior to mechanical removal of the follicle cell layer. The stripped oocytes were washed extensively to remove residual enzyme and maintained in OR-3 at $18^{\circ} \mathrm{C}$ for $24 \mathrm{hr}$ before injection. A pipette beveled to $10 \mu \mathrm{m}$ outer diameter was used 

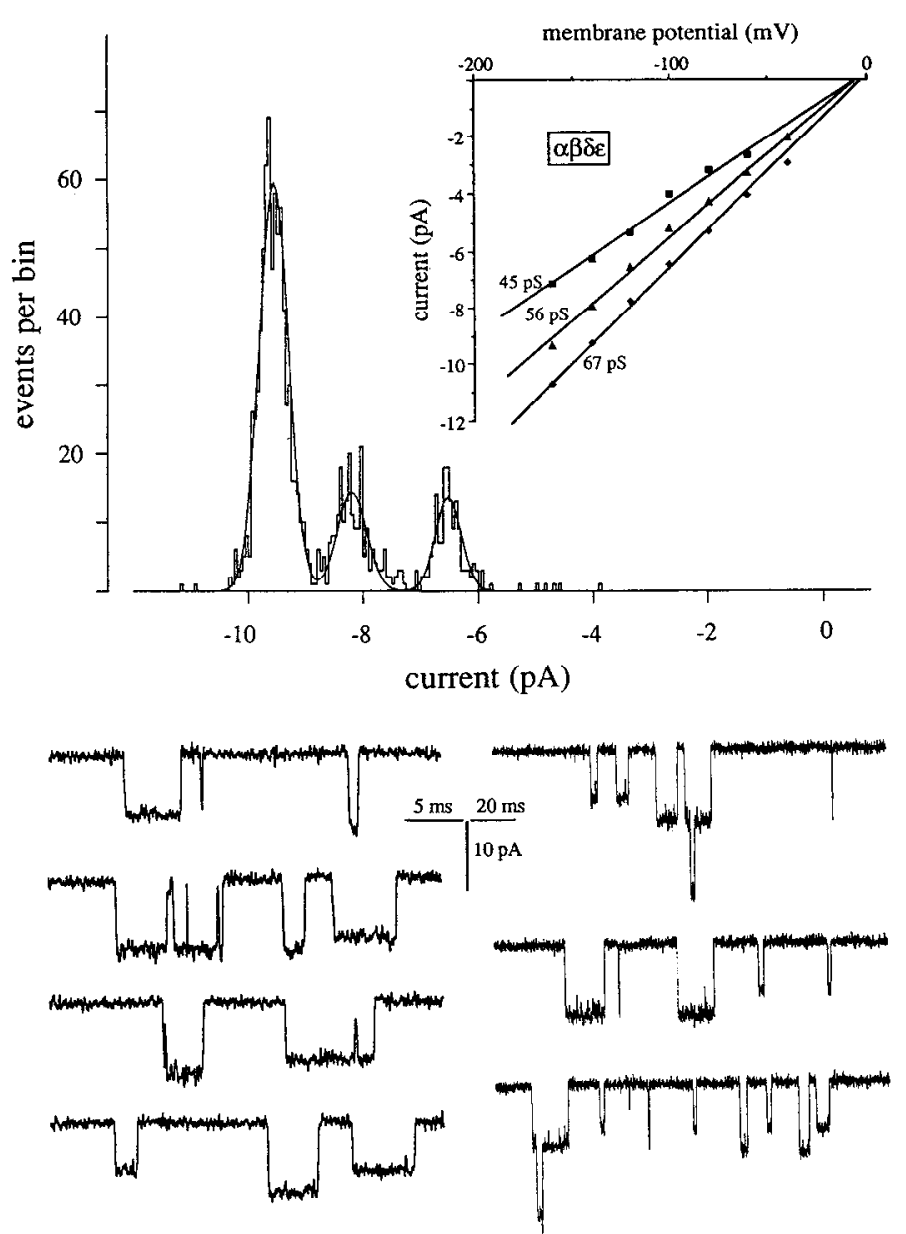

Figure 1. Three amplitude classes can be recorded in patches with $\alpha \beta \delta \epsilon$ channels. Single-channel recordings of $\alpha \beta \delta \epsilon$ channels activated by 100 nM ACh are shown on two different time bases. The outside-out patch was taken from an oocyte injected $3 \mathrm{~d}$ earlier with cRNA. The amplitude distribution for single-channel events shows three different amplitude classes. The longest-duration events from each amplitude class were used to construct the current-voltage relations for the three different channel classes.

to inject approximately $100 \mathrm{nl}$ of RNA mixture into each oocyte. The injected oocytes were maintained in OR-3 for several weeks with no change in appearance and recordings were made within the first week following injection.

Expression of functional receptors was assessed by two-electrode voltage-clamp measurement (DAGAN, TEV 200) of membrane current. The current responses of individual oocytes were compared by application of a standard test solution containing $10 \mu \mathrm{M}$ ACh at a membrane potential of $-100 \mathrm{mV}$. The recording and test solutions contained (in mM) $120 \mathrm{NaCl}, 1 \mathrm{KCl}, 1.8 \mathrm{CaCl}_{2}$, and $10 \mathrm{HEPES}(\mathrm{pH} 7.2$ ). For singlechannel measurements, the oocytes were first placed in a high osmotic solution containing (in $\mathrm{mM}$ ) $200 \mathrm{~K}$-aspartate, $10 \mathrm{KCl}$, and $10 \mathrm{HEPES}$ for 10-15 min to remove the vitelline envelope mechanically (Kullberg et al., 1990). The recording and test solutions used for single-channel recordings contained (in $\mathrm{mM}$ ) $115 \mathrm{NaCl}, 1 \mathrm{KCl}, 0.2 \mathrm{CaCl}_{2}, 1 \mathrm{mM} \mathrm{MgCl}_{2}$, and 10 HEPES (pH 7.2). Patch electrodes (1-3 $\mu \mathrm{m}$ outer tip diameter) were coated with Sigmacote (Sigma), lightly fire polished, and filled with a solution containing $80 \mathrm{mM} \mathrm{KF}, 20 \mathrm{mM} \mathrm{KCl}, 10 \mathrm{~mm} \mathrm{~K}-E G T A$, and $10 \mathrm{~mm}$ HEPES ( $\mathrm{pH}$ 7.4). All recordings were obtained from outsideout excised patches that were removed from the animal hemisphere of the oocyte. At membrane potentials of $-100 \mathrm{mV}$ such patches rarely exhibited channel openings in the absence of applied ACh. ACh was applied to the patch at concentrations between $100 \mathrm{nM}$ and $10 \mu \mathrm{M}$ by a means of rapid flow chamber. Channel events were continuously digitized at $20 \mathrm{kHz}$ on an ITC-16 A/D converter and filtered at $4 \mathrm{kHz}$ by a digital Bessel filter, and the records were analyzed using a threshold analysis of continuous data (TAC) routine (Instrutech Inc.). The detection threshold for events was set to half amplitude for the smallest- amplitude class and the open duration was measured at the half amplitude for each event. Events briefer than $100 \mu \mathrm{sec}$ were incompletely resolved, requiring that corrections be made to estimate the actual open duration. Thus, events between $40 \mu \mathrm{sec}$ (the briefest resolvable event duration) and $100 \mu \mathrm{sec}$ were corrected according to the methods of Colquhoun and Sigworth (1983). Amplitude histograms were fit with either one, two, or three Gaussian distributions to separate amplitude classes. The channel open time for each amplitude class was individually analyzed by fitting the log-open duration histograms of each amplitude class to either two or three exponential functions. The estimates of open time obtained by these fits are still likely to be overestimated due to the undetected brief channel closures.

\section{Results}

Coexpression of $\alpha \beta \delta \epsilon$ subunits results in three functionally distinct receptor types

The role of the $\epsilon$ subunit in ACh receptor function was tested by injecting cRNAs encoding either the mouse or rat $\epsilon$ subunit in combination with mouse $\alpha \beta \delta$ subunit cRNAs. Receptors containing either rat or mouse $\epsilon$ expressed equally well, and we detected no differences in receptor function at the single-channel level. Consequently, no distinction is made between the data obtained with rat and mouse $\epsilon$ cRNAs. Typically, the peak current elicited by $100 \mu \mathrm{M} \mathrm{ACh}$ was greater than $1 \mu \mathrm{A}$ (at -100 $\mathrm{mV}$ ) within $24 \mathrm{hr}$ after injection of $\alpha \beta \delta \epsilon \mathrm{cRNAs}$. The peak oocyte current continued to increase over the period of $5 \mathrm{~d}$ to an average of $30 \mu \mathrm{A}$ with values reaching $100 \mu \mathrm{A}$. This average current corresponds to approximately 5 million $\mathrm{ACh}$ receptors per oocyte, but is likely to be an underestimate of actual channel number because of desensitization. As a result of this high channel density, it was possible to record ACh-activated channels in every outside-out patch tested, even at only $24 \mathrm{hr}$ after injection.

Single-channel recordings of $\mathrm{ACh}$-activated currents made at low concentrations of ACh (100 nM) are shown in Figure 1. The single-channel events were considered to be openings by nicotinic ACh receptors on the basis of two criteria. First, in every patch analyzed, no openings were observed for $2 \mathrm{~min}$ in the absence of ACh (see Fig. 3). Second, all events were blocked by application of $100 \mathrm{nM} \alpha$-bungarotoxin. In approximately $5 \%$ of patches derived from the animal hemisphere, we observed endogenous channel activity in the absence of $\mathrm{ACh}$, and these patches were not analyzed. The occurrence of non-ACh-activated channels was substantially higher in patches derived from vegetal pole membrane, consistent with the reported localization of endogenous channels in oocytes (Barnard et al., 1982).

Every outside-out patch examined showed at least two, and as many as three, current amplitude classes when more than 500 openings were analyzed (Figure 1). The ACh-activated channels shared a common reversal potential $(-7 \mathrm{mV})$ and were all activated by very low ACh concentrations (10 nM). No concentrations of $\mathrm{ACh}$ were found that would allow selective activation of the different amplitude classes. Assignment of an amplitude class to the high, intermediate, or low conductance type was based on the differences in slope conductance. The individual values for each conductance class measured in the 13 patches are given in Figure 1. Because the channel currents exhibited slight inward rectification, the slope conductance was computed between -60 and $-140 \mathrm{mV}$. In 13 patches the mean slope conductances for the high ( $71 \pm 5 \mathrm{pS})$, intermediate (59 $\pm 6 \mathrm{pS}$ ), and low (42 $\pm 7 \mathrm{pS}$ ) channel types were obtained (Fig. 2 , top). Of the 13 patches, 10 cxhibited openings by all three classes and three lacked openings by the low-conductance channel type. 


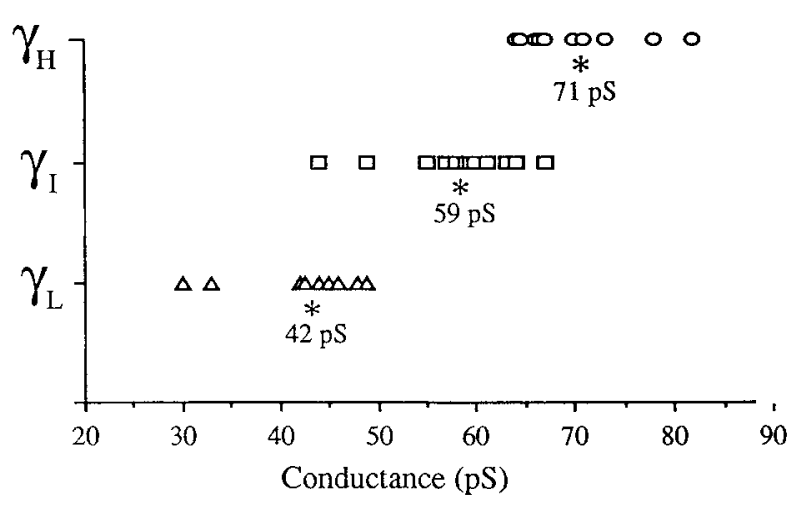

$\alpha \beta \delta \varepsilon$ Channel Composition

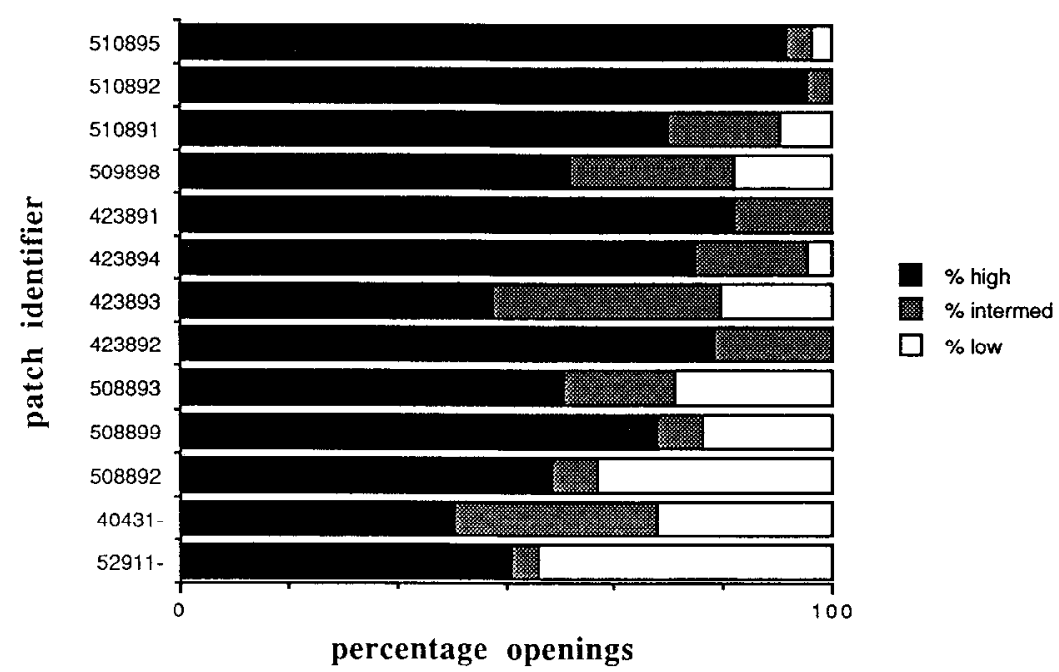

Figure 2. The three amplitude classes correspond to different conductance classes. Top, The distribution of conductances computed for each of the three amplitude classes observed with $\alpha \beta \delta \epsilon$ channels. Each value for conductance is computed from a different outsideout patch. The mean values for each conductance class $\left(\gamma_{L}, \gamma_{L o w} ; \gamma_{L}, \gamma_{\text {Intermediate }}\right.$; $\left.\gamma_{H}, \gamma_{\mathrm{High}}\right)$ are indicated. Bottom, The contribution by each conductance class is shown for 13 different outside-out patches. The fractional opening by each conductance class at $100 \mathrm{nM}$ ACh (indicated as a percentage) is shown for each patch.
In 13 patches where functional identification of each conductance class was made, the patch composition was obtained by computing the fraction of channel openings by high-, intermediate-, and low-conductance channels (Fig. 2, bottom). The high-conductance channel was the predominantly active channel, comprising over $40 \%$ of the openings in all patches tested and averaging $69 \pm 18 \%$ overall of the 13 patches examined. The openings by low and intermediate channels were equally distributed at $15 \pm 10 \%$ and $15 \pm 15 \%$ of the total, respectively. Obtaining these estimates was complicated by the nonstationary behavior of the intermediate- and low-conductance channel class. For example, the lowest-amplitude class would often completely disappear during a 5-10 min recording period, while in a small number of patches no evidence of drop out was observed. To minimize the variability due to time-dependent channel drop out, the data presented in Figure 2 are derived from the first 2 min following initial application of $100 \mathrm{~nm}$ to the patch held at $-100 \mathrm{mV}$.

To demonstrate further that all three conductance classes represented openings by ACh receptors, high concentrations of ACh $(10 \mu \mathrm{M})$ were applied to a patch containing all three classes. Application of $10 \mu \mathrm{M}$ ACh resulted in rapid desensitization, reflected by a time-dependent decay of the macroscopic patch current (Fig. 3). Single-channel recordings following the onset of desensitization indicated that all three conductance classes burst at this concentration verifying that all three channel types are $\mathrm{ACh}$ receptors.

\section{The multiple forms of $\alpha \beta \delta \epsilon$ channels do not result from} subunit omission

The amplitude-duration distribution for events from a single patch at $100 \mathrm{~nm}$ ACh shows that all three conductance classes for $\alpha \beta \delta \epsilon$ channels had brief open times (Fig. $4 B$ ), compared to previous studies on $\alpha \beta \delta \gamma$ channels (see Fig. 7). It was not possible in most patches to achieve complete separation between conductance classes. Consequently, the analysis of channel open times was only performed at membrane potentials of -80 and $-100 \mathrm{mV}$, where optimal separation was achieved. In the patches where three amplitude classes were clearly resolved, the distribution of large- and intermediate-amplitude events consistently extended to longer durations than seen for the smallestamplitude classes. In most cases the open-duration histograms for all three amplitude class events were well fitted by the sum of two exponential curves. Overall, the fast and slow time constants of the fits were not significantly different between the three different channel classes (Fig. 4A). The slow time constants averaged $3.9 \pm 1.2 \mathrm{msec}$ for the high, $4 \pm 1.7 \mathrm{msec}$ for the intermediate, and $2.7 \pm 1.1 \mathrm{msec}$ for the low-conductance channel type. The fast time constants averaged $0.35 \pm 0.15 \mathrm{msec}$ for the high, $0.33 \pm 0.18 \mathrm{msec}$ for the intermediate, and $0.24 \pm$ $0.23 \mathrm{msec}$ for the low conductance type. In approximately $30 \%$ of the open duration histograms an additional intermediate component with time constant between 2 and $3 \mathrm{msec}$ was required for best fit (see Fig. 5). 
Figure 3. All three amplitude classes desensitize in response to $10 \mu \mathrm{M} \mathrm{ACh}$. Upper left, The responses to low $(0.1$ $\mu \mathrm{M})$ and high $(10 \mu \mathrm{M}) \mathrm{ACh}$ are indicated on a slow time scale. Fast desensitization is observed in response to the high concentration. Below, During maintained application of $10 \mu \mathrm{M} \mathrm{ACh}$, all three amplitude classes (each level shown by a broken line) exhibit clustered openings, characteristic of desensitized receptors. An apparent transition between the two higher-conductance states is indicated by an asterisk. Upper right, The current-voltage relationship for the three amplitude classes at desensitizing concentrations of ACh yield values for slope conductance that are like those at low concentration.
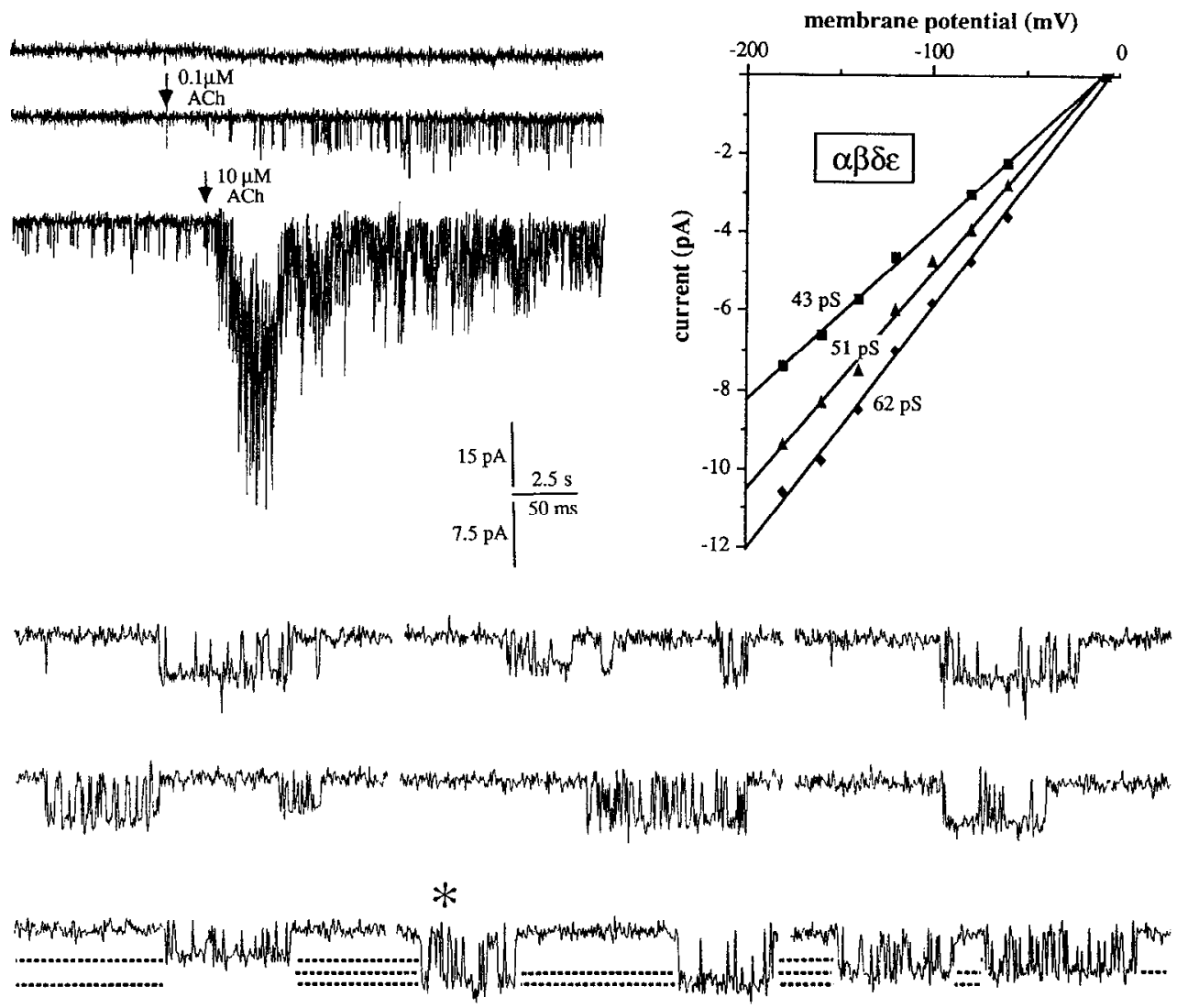

The open duration of all three conductance classes was briefer than any of the channel classes observed with $\alpha \beta \delta \gamma$ subunits (Kullberg et al., 1990). The overall time constants derived from two exponential fits were $0.32 \pm 0.21 \mathrm{msec}$ and $3.7 \pm 1.4 \mathrm{msec}$ when openings by all three $\alpha \beta \delta \epsilon$ channel types were pooled. This compares to overall time constants of $0.3 \mathrm{msec}$ and $10.1 \mathrm{msec}$ for the channel events associated with $\alpha \beta \delta \gamma$ subunits (Kullberg et al., 1990).

In previous studies the multiple conductance classes observed upon injection of $\alpha \beta \delta \gamma$ were shown to result from channels in which either the $\gamma$ or $\delta$ subunits were missing (Kullberg et al., 1990; Jackson et al., 1990). We therefore considered the possibility that a similar process was responsible for the multiple conductance classes observed after $\alpha \beta \delta \epsilon$ injection. All theoretical subunit combinations resulting from expression of $\alpha \beta \delta \epsilon$ cRNAs were tested by eliminating one or more subunit cRNAs from the injection mixture. Only two combinations that lacked an $\epsilon$ subunit resulted in functional expression, $\alpha \delta$ and $\alpha \beta \delta$ (Liu et al., 1991). Both $\alpha \delta$ and $\alpha \beta \delta$ channels exhibited long mean channel open times when expressed in oocytes (Mishina et al., 1986; Yu et al., 1989; Kullberg et al., 1990; Liu et al., 1991), thereby distinguishing them from all three channel classes observed in oocytes injected with $\alpha \beta \delta \epsilon$ CRNAs. One combination of $\epsilon$-containing channels was found to express in the absence of one or more subunits. Receptors not containing $\beta$ ( $\alpha \delta \epsilon)$ expressed microamp currents, potentially accounting for part of the functional diversity observed with $\alpha \beta \delta \epsilon$ cRNA injections. The expression levels of this combination, however, were highly variable between experimental groups of oocytes. Of ten groups of oocytes injected with $\alpha \delta \epsilon$ RNAs, four exhibited mean responses less than $70 \mathrm{nA}$ at $-100 \mathrm{mV}$ in response to $10 \mu \mathrm{M} \mathrm{ACh}$. Four groups showed intermediate levels of expression with average currents of $500 \mathrm{nA}$ and only two groups exhibited high levels of expression with responses as high as $6.5 \mu \mathrm{A}$.

To determine whether $\alpha \delta \epsilon$ receptors accounted for the lowerconductance channels observed in $\alpha \beta \delta \epsilon$ injected oocytes, the $\alpha \delta \epsilon$ receptors were studied at the single-channel level. Every patch tested from the $\alpha \delta \epsilon$-injected oocytes that had macroscopic currents greater than $1 \mu \mathrm{A}$ contained ACh-activated channels. Three different amplitude classes of channels were observed in $\alpha \delta \epsilon-$ injected oocytes with mean slope conductances corresponding to $63.4 \pm 1.7 \mathrm{pS}, 52.6 \pm 5.1 \mathrm{pS}$, and $40.0 \pm 6.4 \mathrm{pS}$ (Fig. 5). These values were not significantly different from those measured for the three different conductance groups seen in oocytes injected with $\alpha \beta \delta \epsilon$. Measurements of channel open durations also indicated functional similarities between the $\alpha \delta \epsilon$ and the $\alpha \beta \delta c$ channels. The open duration histograms of $\alpha \delta \epsilon$ were fit by the sum of two exponential components with fast and slow time constants similar to those described for $\alpha \beta \delta \epsilon$. As seen with $\alpha \beta \delta \epsilon$, approximately $30-50 \%$ of the histograms required a third intermediate component for the best fit (Fig. 5). The slow time constant for the $\alpha \delta \epsilon$ classes measured $4.5 \pm 1.3 \mathrm{msec}, 4.9 \pm 2.1$ $\mathrm{msec}$, and $3.5 \pm 1.7 \mathrm{msec}$ for the highest to lowest conductance, respectively. These estimates compare to $3.9 \mathrm{msec}, 4.0 \mathrm{msec}$, and $2.7 \mathrm{msec}$ obtained for the three conductance classes with $\alpha \beta \hat{\delta}$.

\section{Concentration dependence of $A C h$ receptors containing $\epsilon$ or $\gamma$ subunits}

The ACh dose-response relations were compared for $\gamma$ - and $\epsilon$-containing receptors by two-microelectrode voltage-clamp measurement. For this purpose, the perfusion speed was max- 
imized and concentration jumps were achieved within 2 sec of application. Even with this rapid application, it is likely that significant desensitization occurred before peak current was achieved leading to an underestimation of the current at higher concentrations. A second source of error with these experiments was a systematic decrease in the peak current observed upon repeated applications of high concentrations of $\mathrm{ACh}$. This error was minimized by testing the lowest $\mathrm{ACh}$ concentrations at the outset, washing thoroughly, and allowing 5-10 min between ACh applications.

The dose-response relations for $\alpha \beta \delta \gamma$ and $\alpha \beta \delta \epsilon$ receptors were fitted to obtain Hill coefficients and estimates of half-saturating concentrations of $\mathrm{ACh}$ (Fig. 6). Responses were normalized to the current measured at $100 \mu \mathrm{M}$ under the assumption that this concentration is saturating (Fig. 6). The dose-response relations obtained for $\alpha \beta \delta \gamma$ and $\alpha \beta \delta \epsilon$ showed an overall difference when the recordings were made within $3 \mathrm{~d}$ following cRNA injection. Specifically, the relations were shifted to the left for $\alpha \beta \delta \gamma$, indicating greater activation by $\mathrm{ACh}$ at equivalent concentrations. The ACh concentration that resulted in half-maximal activations measured $1.4 \pm 0.2 \mu \mathrm{M}$ for $\alpha \beta \delta \gamma$ and $4.8 \pm 1.4 \mu \mathrm{M}$ for $\alpha \beta \delta \epsilon$. The sensitivity to ACh did not differ for $\alpha \beta \delta \gamma$ and $\alpha \beta \delta \epsilon$ oocytes when recordings were made at $4 \mathrm{~d}$ or more after cRNA injection. The values obtained for longer times of expression were $2.0 \pm 0.6 \mu \mathrm{M}$ for $\alpha \beta \delta \gamma$ and $1.8 \pm 0.7 \mu \mathrm{M}$ for $\alpha \beta \delta \epsilon$. At all times following injection, the estimated Hill coefficient was similar for $\alpha \beta \delta \epsilon(1.8 \pm 0.4)$ and $\alpha \beta \delta \gamma(1.9 \pm 0.6)$. Comparisons of ACh-activated current trajectories from $\alpha \beta \delta \gamma$ and $\alpha \beta \delta \epsilon$ receptors revealed a consistent trend of more complete desensitization in oocytes injected with $\alpha \beta \delta \epsilon$. It was not possible to compare quantitatively the fast component of desensitization due to the slow perfusion speed. However, the traces shown in Figure 6 compare the complete decline in ACh-activated current for $\alpha \beta \delta$ f oocytes with a large residual current in $\alpha \beta \delta \gamma$-injected oocytes.

\section{Discussion}

Three amplitude classes of ACh-activated single-channcl currents were consistently observed in Xenopus oocytes injected with cRNAs encoding $\alpha \beta \delta \epsilon$ subunits. All three classes exhibited slight inward current rectification, shared the same reversal potential, were blocked by $\alpha$-bungarotoxin, and showed desensitization kinetics in response to $10 \mu \mathrm{M} \mathrm{ACh}$, indicating that the events represented openings by $\mathrm{ACh}$ receptor channels. The three classes differed in single-channel conductances ( $71 \mathrm{pS}, 59$ $\mathrm{pS}$, and $42 \mathrm{pS}$ ), and on this criterion we consider each conductance class to represent a distinct receptor type.

What is the subunit composition of these three functionally distinct receptor types? It has been shown previously that receptors lacking a subunit can account for functional diversity. For example, in the case of slow types of receptors, omission of either the $\delta$ (Kullberg et al., 1990) or $\gamma$ (Jackson et al., 1990) subunits accounts for much of the observed functional diversity in conductance classes. Moreover, significant numbers of channels lacking both $\delta$ and $\gamma$ are expressed in cells injected with $\alpha \beta \delta \gamma$ cRNAs and no evidence of fast channel function is observed (Fig. 7). Omission of subunits is not a mechanism underlying the multiple channel classes expressed from $\alpha \beta \delta \epsilon \mathrm{cRNAs}$. Of all possible subunit combinations resulting from injection of $\alpha \beta \delta \epsilon$ cRNAs, only three combinations ( $\alpha \delta, \alpha \beta \delta$, and $\alpha \delta \epsilon)$, which lacked one or more subunits, resulted in functional expression. Consequently, only these three combinations could potentially
A

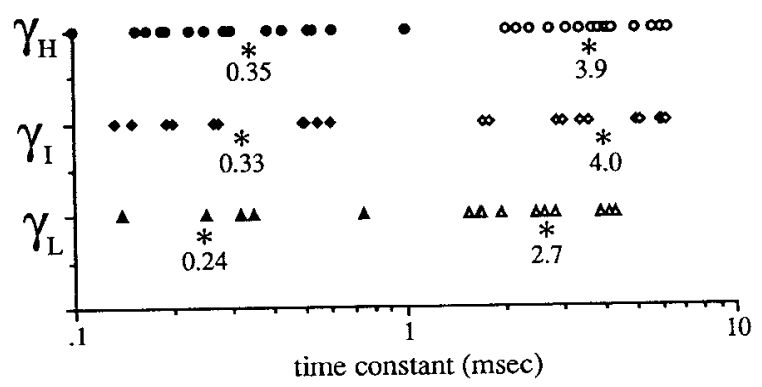

B

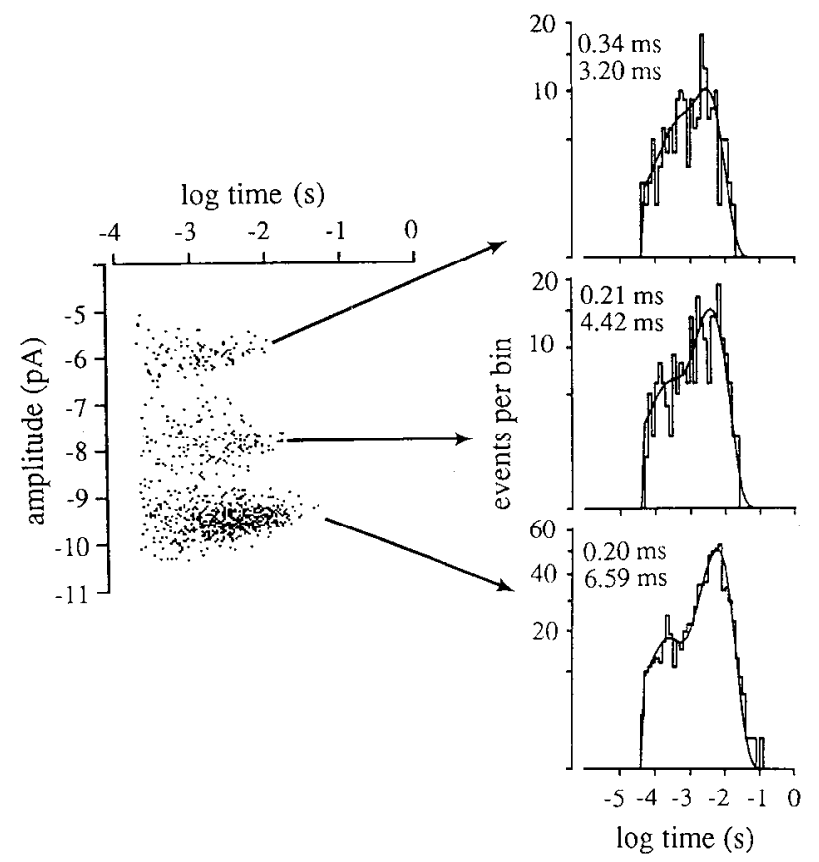

Figure 4. The three different amplitude classes all have fast kinetics. $A$, The distribution of time constants for fast (solid symbols) and slow (open symbols) components of the fitted duration histograms of individual patches. The overall mean values for fast and slow components of all three conductance classes are indicated. $B$, Amplitude-duration scatter plot for events recorded from a single outside-out patch $\left(V_{m}=\right.$ $-100 \mathrm{mV}$ ) exhibiting all three $\alpha \beta \delta \epsilon$ channel classes. The log-duration histograms for each of the amplitude classes is shown fitted to two exponentials with indicated time constants.

result in expression of the functional subtypes. The combinations $\alpha \delta$ and $\alpha \beta \delta$ exhibit long mean channel open times when expressed in oocytes (Mishina et al., 1986; Yu et al., 1989; Liu et al., 1991). These slow kinetics distinguish them from all three channel classes observed in oocytes injected with $\alpha \beta \delta \epsilon$ cRNAs. The third possibility (channels lacking $\beta$ ) can be excluded on the grounds that expression of receptors from $\alpha \delta \epsilon \mathrm{cRNAs}$ is very low. Moreover, the three channel classes from $\alpha \delta \epsilon$ receptors are functionally indistinguishable from those observed with the full complement of subunits. Taken together, the findings are most consistent with the idea that all three receptor types are composed of $\alpha_{2} \beta \delta \epsilon$.

Several additional mechanisms could potentially account for the multiple conductances observed with a single receptor stoichiometry of $\alpha_{2} \beta \delta \epsilon$. First, a single ACh receptor may adopt different conductance states, as shown to occur for transitions into subconductance states (Hamill and Sakmann, 1981; Auerbach and Sachs, 1983; Colquhoun and Sakmann, 1985). At low ACh 


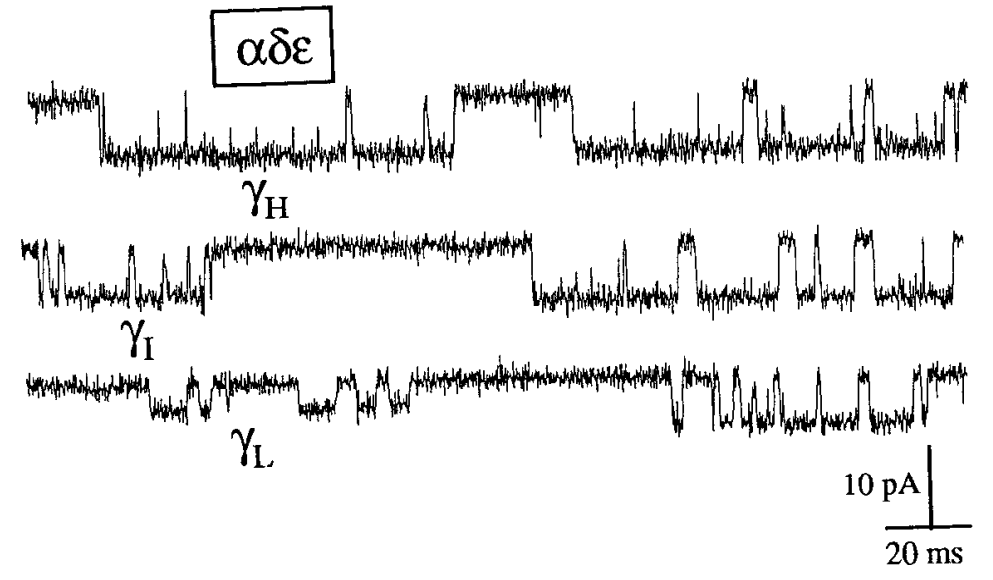

membrane potential $(\mathrm{mV})$

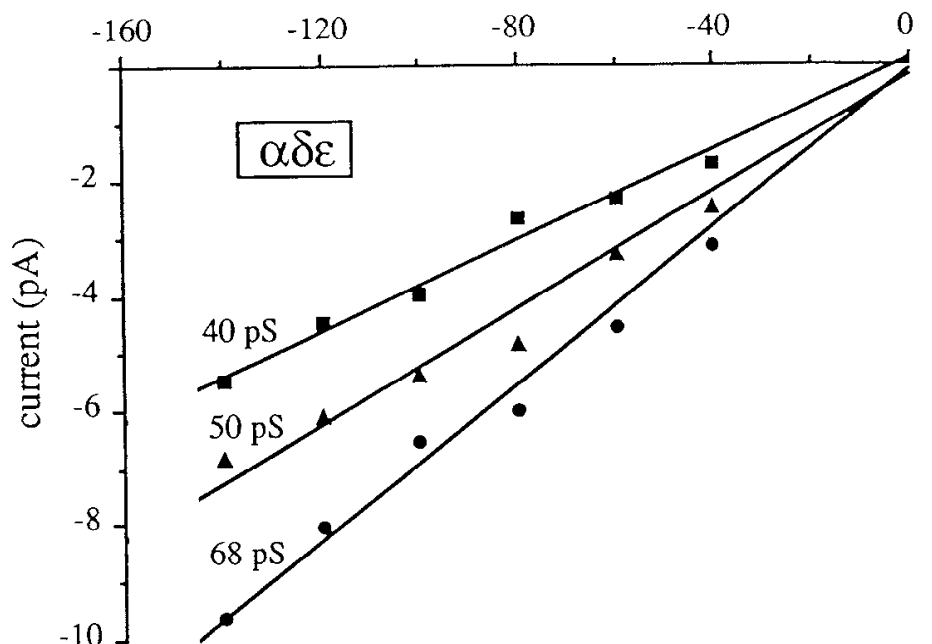

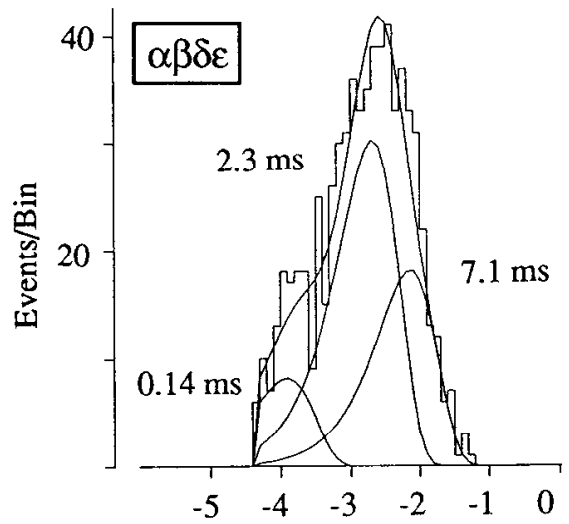

$\log$ open duration (s)

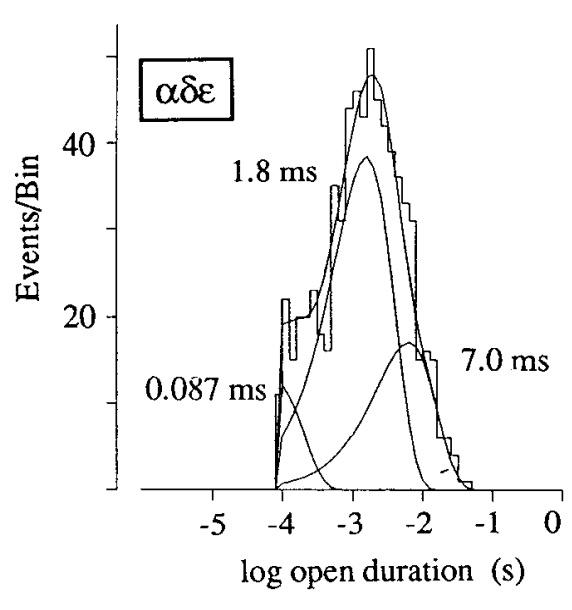

Figure 5. The properties of $\alpha \delta \epsilon$ channels are identical to $\alpha \beta \delta \epsilon$ channels. Upper left, Single-channel recordings of $\alpha \delta \epsilon$ channels demonstrating three different amplitude classes that burst in response to $10 \mu \mathrm{M} \mathrm{ACh}$. Lower left, Current-voltage relations for all three amplitude classes. Right, Combined open duration histograms for all three amplitude classes of $\alpha \beta \delta \epsilon(t o p)$ and $\alpha \delta \epsilon$ (bottom) showing similar time constants of fit.

Figure 6. The $\alpha \beta \delta$ receptors have similar Hill coefficients but show differences in the concentration dependence of activation. Upper left, Responses of two different oocytes to rapid and maintained application of $100 \mu \mathrm{M}$ ACh. Lower lefl, Dose-response relationship between membrane current and ACh concentration obtained by rapid application of ACh. The fractional current (normalized to the maximal current obtained from an individual oocyte) versus $\mathrm{ACh}$ concentration relations is shown for an $\alpha \beta \delta \gamma$ and an $\alpha \beta \delta \epsilon$ oocyte (right). Fach data set was fit to the relationship $I_{\max } /\left[1+(k / x)^{n}\right]$ to determine the Hill coefficients $(n)$ and the concentration resulting in half-maximal activation $(k)$. The overall values \pm SD obtained for 16 oocytes (four different sets of oocytes) are indicated in the accompanying histograms.
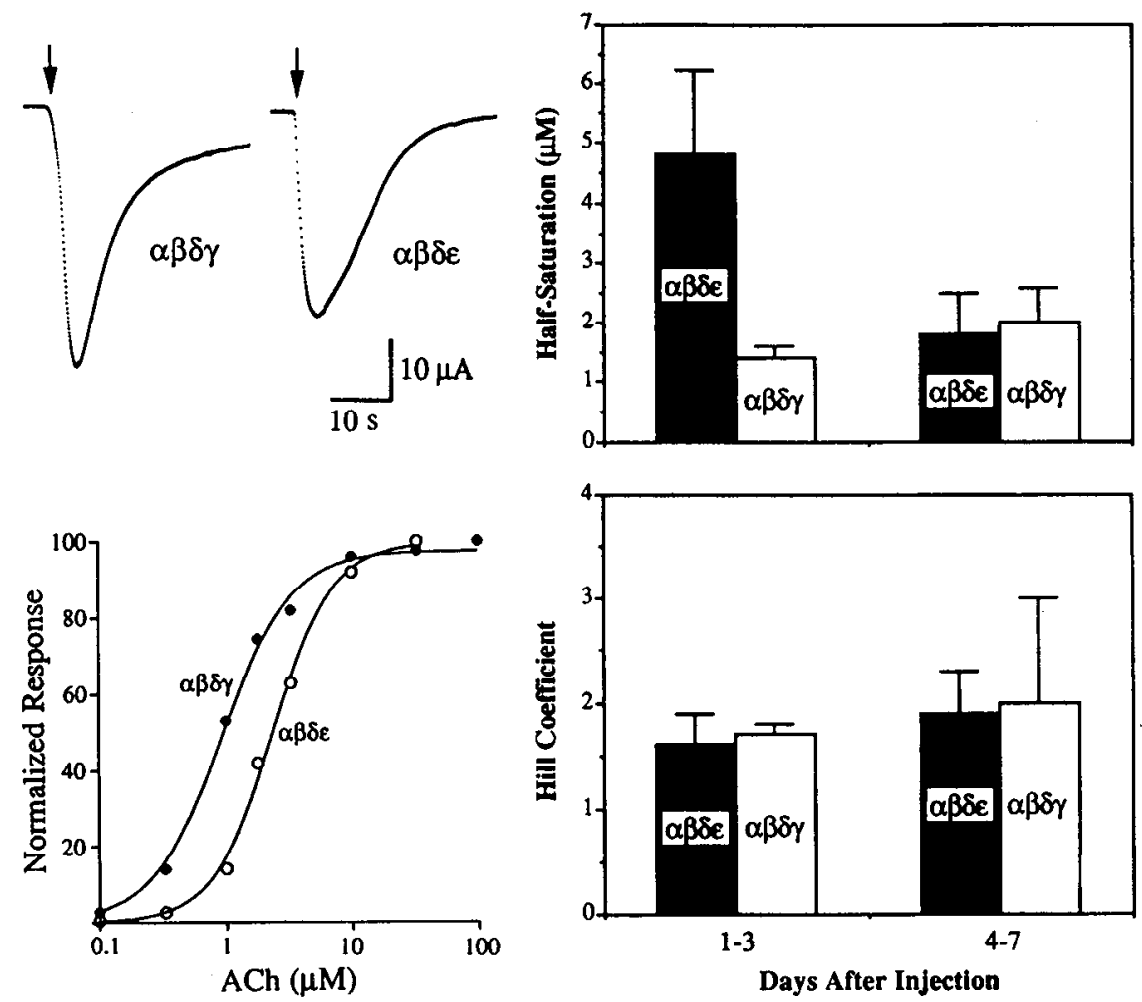


\section{Oocyte $\alpha \beta \delta \gamma$}
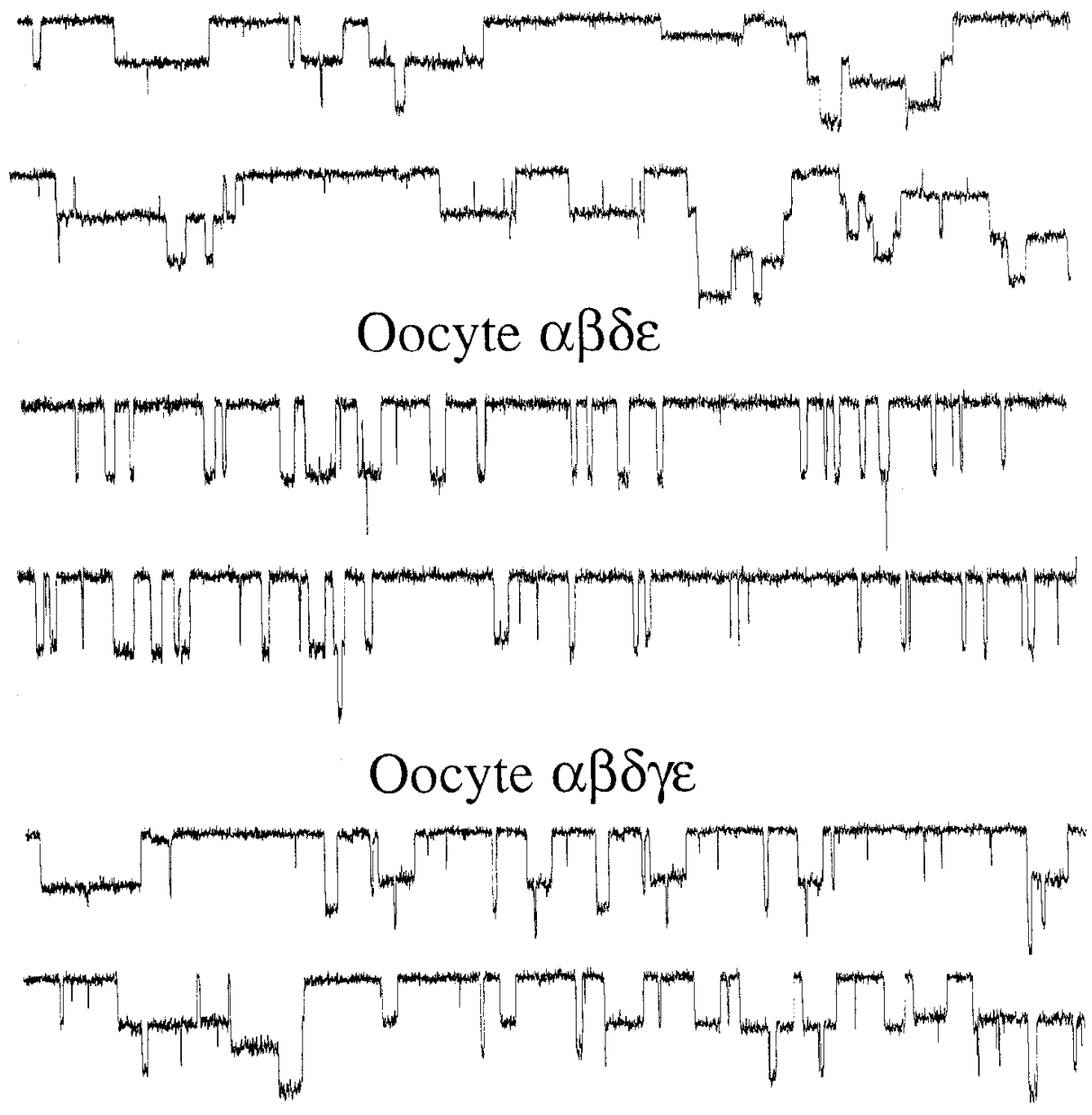

Denervated Muscle

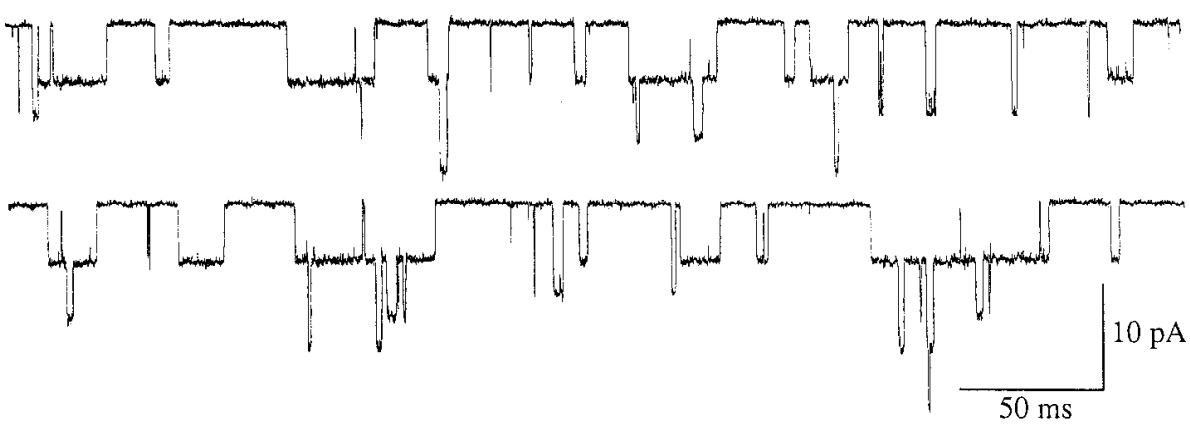

Figure 7. Comparison of single-channel records from oocytes injected with the cRNAs composing embryonic muscle $(\alpha \beta \delta \gamma)$, adult muscle $(\alpha \beta \delta \epsilon)$, and developing and denervated muscle $(\alpha \beta \delta \gamma \epsilon)$. Recordings of ACh-activated channels from $5 \mathrm{~d}$ denervated mouse toe muscle (flexor digitorum brevis) are shown for comparison at the same ACh concentration $(100 \mathrm{nM})$ and membrane potential $(-100 \mathrm{mV})$

concentrations, we observed infrequent transitions among the different amplitude classes, suggesting transitions within a single protein. However, at this low ACh concentration, the possibility that the transitions represented sequential openings by two different receptor types could not be excluded. When we examined the clustered openings at high concentrations of ACh $(10 \mu \mathrm{M})$ where sequential openings occur through the activation of a single receptor, very infrequent apparent transitions between levels were observed (see Fig. 3). Thus, should such transitions between conductance classes occur, they are infrequent. Alternative structural explanations for different conductances include posttranslational modification and differences in subunit ordering within the receptor. For example, alterations in receptor subunit glycosylation (Covarrubias et al., 1989) and phosphorylation (Huganir and Miles, 1989) have been shown to alter receptor kinetics but, importantly, no effects on conductance have been observed (Steinbach and Zempel, 1987). Alternatively, the position of charged residues known to influence channel permeation (Imoto et al., 1988) may vary between receptors. In fact, the positions of the various subunits relative to one another in the receptor molecule are still uncertain for all forms of nicotinic ACh receptors (Karlin, 1987).

The regulation of fast and slow channel types on skeletal muscle have formed the basis of many developmental studies in both amphibians and mammals (for revicw, scc Brehm and Henderson, 1988). These studies have pointed to a highly con- 
served pattern of development in which the proportions of fast channels are regulated by nerve contact. The acquisition of fast channels forms the underpinnings of the fast synaptic currents that are characteristic of synapses in twitch-type muscle. Two events in muscle have been shown to correlate with the transition from slow to fast channel function. One event is the appearance of a channel type with a shorter open time and higher conductance $(\sim 60 \mathrm{pS})$ than any slow type of channel (Brehm et al., 1984; Siegelbaum et al., 1984). A second developmental event is a reduction in open time for a slow channel type $(\sim 50$ pS) without any accompanying change in single-channel conductance (Leonard et al., 1984; Owens and Kullberg, 1989b; Rohrbough and Kidokoro, 1990; Shepherd and Brehm, 1992). The structural basis for the reduction in open time is not known, but previous work has suggested posttranslational modification of the $\alpha_{2} \beta \delta \gamma$ receptor (Carlson and Leonard, 1989). However, recent observations suggest that the open time decrease may be conferred by the $\epsilon$ subunit. Embryonic muscle from Xenopus switches on both fast types of channels during differentiation (Owens and Kullberg, 1989a). The same is true for a mouse skeletal muscle cell line (Shepherd and Brehm, 1992). Importantly, in both cell types, the onset of shortening in open time (event two) coincides precisely with the first appearance of the high-conductance $60 \mathrm{pS}$ channels (event one) known to contain an $\epsilon$ subunit.

The expression studies herein provide further support for $\epsilon$ involvement in the acquisition of two forms of fast channels in muscle. Overall, we are struck by the remarkable recapitulation of muscle receptor function by oocytes. Expression of $\alpha \beta \delta \gamma \epsilon$ cRNAs in oocytes results in an apparent recapitulation of the entire range of receptor types obscrved on cmbryonic, adult, and denervated skeletal muscle (Fig. 7). However, exacting comparisons between receptors expressed in Xenopus oocyte and in native muscle are complicated by the differences in ionic composition of the media. For example, the requirement that divalent concentration be lowered in the case of oocyte recordings results in a higher single-channel conductance than observed for muscle receptors (Imoto et al., 1988).

The available data on $\alpha \beta \delta \gamma$ and $\alpha \beta \delta \epsilon$ receptors suggest that oocytes accurately recapitulate the functional properties seen in mammalian cells. $\alpha \beta \delta \gamma$ receptors measure $50 \mathrm{pS}$ with mean channel open times of approximately $10 \mathrm{msec}$ in oocytes (Kullberg et al., 1990; see Fig. 7). This compares favorably to the 45 $\mathrm{pS}$ conductance and $7.5 \mathrm{msec}$ open time reported for receptors in denervated mouse skeletal muscle (Henderson et al., 1987). The predominant class of receptors, in adult mouse skeletal muscle, measures $60-65 \mathrm{pS}$ with mean channel open times of 2-3 msec (Brehm and Kullberg, 1987). This corresponds well to $71 \mathrm{pS}$ and $4 \mathrm{msec}$ measured from $\alpha \beta \delta \epsilon$ receptors expressed in oocytes. Additional support for the idea that receptors expressed in oocytes are functionally similar to those in mammalian cells comes from studies on mammalian COS cells transfected with cDNAs encoding $\alpha \beta \delta \epsilon$ subunits. Three conductance classes were observed in COS cells ( $60 \mathrm{pS}, 45 \mathrm{pS}, 28 \mathrm{pS})$, similar to the three classes observed in oocytes. These three conductances were 20-35\% lower than the corresponding conductances measured in oocytes, but this reduction in single-channel conductance is expected on the basis of the threefold higher divalent concentrations used for COS cell recordings.

The present findings suggest that the highest-conductance channel type (70 pS) in $\alpha \beta \delta \epsilon$ injected oocytes probably corresponds to the $60-65$ pS channel type that predominates in adult muscle. Either of the lower-conductance $\alpha \beta \delta \epsilon$ forms is a candidate for a second fast class of $50 \mathrm{pS}$ channels in developing channels (Shepherd and Brehm, 1992) and $42 \mathrm{pS}$ channels in adult (Brehm and Kullberg, 1987) muscle. However, the most likely candidate is the intermediate-conductance channel type observed in oocytes. When corrected for differences in recording solution composition, the average conductance becomes approximately $50 \mathrm{pS}$, much like the values reported for muscle receptors. Additional agreement is observed between time constants for channel closing (at membrane potentials of $-100 \mathrm{mV}$ ) reported for these channels in oocytes $(\sim 4 \mathrm{msec})$ and in muscle ( $\sim 5-6 \mathrm{msec}$ ). Thus, on the basis of functional comparisons alone, the intermediate-conductance channel type observed in oocytes is likely to reflect a fast channel counterpart in developing muscle. Our findings raise the interesting possibility that the appearance of the $\epsilon$ subunit underlies dual developmental switches to fast channel functioning in skeletal muscle.

\section{References}

Auerbach A, Sachs F (1983) Flickering of a nicotinic ion channel to a subconductance state. Biophys J 42:1-10.

Barnard EA, Miledi R, Sumikawa K (1982) Translation of exogenous messenger RNA coding for nicotinic acetylcholine receptors produces functional receptors in Xenopus oocytes. Proc R Soc Lond [Biol] 215: 241-246.

Brehm P (1989) Resolving the structural basis for developmental changes in muscle ACh receptor function: it takes nerve. Trends Neurosci 12:174-176.

Brehm P, Henderson L (1988) Regulation of acetylcholine receptor channel function during development of skeletal muscle. Dev Biol 129:1-11.

Brehm P, Kullberg RW (1987) Acetylcholine receptor channels on adult mouse skeletal muscle are functionally identical in synaptic and nonsynaptic membrane. Proc Natl Acad Sci USA 84:2550-2554.

Brehm P, Kullberg R, Moody-Corbett F (1984) Properties of nonjunctional acetylcholine receptor channels on innervated muscle of Xenopus laevis. J Physiol (Lond) 350:631-648.

Camacho P, Goodman R, Mandel G, Brehm P (1989) Isolation of a cDNA encoding the epsilon subunit of the rat muscle ACh receptor. Biophys J 55:554a.

Carlson GC, Leonard RJ (1989) Developmental changes in open time and conductance of acetylcholine receptors in aneural cultured Xenopus myocytes treated with cycloheximide or tunicamycin. Dev Brain Res 46:61-68.

Colquhoun D, Sakmann B (1985) Fast events in single channel currents activated by acetylcholine and its analogs at the frog muscle endplate. J Physiol (Lond) 369:501-557.

Colquhoun D, Sigworth F (1983) Fitting and statistical analysis of single-channcl records. In: Single channel recording (Neher E, Sakmann B, eds), pp 191-263.

Covarrubias M, Kopta C, Steinbach JH (1989) Inhibition of asparagine-linked oligosaccharide processing alters the kinetics of the nicotinic acetylcholine receptor. J Gen Physiol 93:765-783.

Criado M, Koenen M, Sakmann B (1990) Assembly of an adult type acetylcholine receptor in a mouse cell line transfected with rat muscle $\epsilon$ subunit DNA. FEBS Lett 270:95-99.

Gu Y, Franco A, Gardner P, Lansman J, Forsayeth J, Hall Z (1990) Properties of embryonic and adult muscle acetylcholine receptors transiently expressed in COS cells. Neuron 5:147-157.

Gu Y, Camacho P, Gardner P, Hall Z (1991) Identification of two amino acids residues in the epsilon subunit that promote mammalian muscle acetylcholine receptor assembly in COS cells. Neuron 6:879887.

Hamill O, Sakmann B (1981) Multiple conductance states of single acetylcholine receptor channel in embryonic muscle cells. Nature 294: $462-464$.

Henderson L, Brehm P (1989) The single channel basis for the slow kinetics of synaptic currents in vertebrate slow muscle fibers. Neuron 2:1399-1405.

Henderson L, Lechleiter J, Brehm P (1987) Single channel properties 
of newly synthesized acetylcholine receptors following denervation of mammalian skeletal muscle. J Gen Physiol 89:999-1014.

Huganir R, Miles K (1989) Protein phosphorylation of nicotinic acetylcholine receptors. Crit Rev Biochem Mol Biol 24:183-214.

Imoto K, Busch C, Sakmann B, Mishina M, Konno T, Nakai J, Bujo H, Mori Y, Fukuda K, Numa S (1988) Rings of negatively charged amino acids determine the acetylcholine receptor channel conductance. Nature 335:645-648.

Jackson M, Imoto K, Mishina M, Kono T, Numa S, Sakmann B (1990) Spontaneous and agonist-induced openings of an acetylcholine receptor channel composed of bovine muscle $\alpha, \beta$, and $\delta$ subunits. Pfluegers Arch 417:129-135.

Karlin A (1987) Going round in receptor circles. Nature 329:286289.

Kullberg R, Owens JI, Camacho P, Mandel G, Brehm P (1990) Multiple conductance classes of mouse nicotinic acetylcholine receptors expressed in Xenopus oocytes. Proc Natl Acad Sci USA 87:20672071.

Leonard RJ, Nakajima S, Nakajima Y, Takahashi T (1984) Differential development of two classes of acetylcholine receptors in Xenopus muscle in culture. Science 226:55-57.

Liu Y, Zheng Y, Camacho P, Mandel G, Brehm P (1991) Functional differences between $\mathrm{ACh}$ receptor channels containing gamma and epsilon subunits. Biomed Res 12:83-85.

Mishina M, Takai T, Imoto K, Noda M, Takahashi T, Numa S, Methfessel C, Sakmann B (1986) Molecular distinction between fetal and adult forms of muscle acetylcholine receptor. Nature 321:406-411.

O'Leary ME, White $M$ (in press) Mutational analysis of ligand-induced activation of the Torpedo acetylcholine receptor. J Biol Chem, in press.
Owens J, Kullberg R (1989a) In vivo development of nicotinic acetylcholine receptor channels in Xenopus myotomal muscle. J Neurosci 9:1018-1028.

Owens J, Kullberg R (1989b) Three conductance classes of nicotinic acetylcholine receptors are expressed in developing amphibian skeletal muscle. J Neurosci 9:2575-2580.

Rohrbough J, Kidokoro Y (1990) Changes in kinetics of acetylcholine receptor channels after initial expression in Xenopus myocyte culture. J Physiol (Lond) 425:245-269.

Salpeter MM, Buonanno A, Pinset C, Mulle C, Benoit P, Changeux JP, Chelly J, Gros F, Montarras D, Brehm P, Shepherd D, Froehner S, Gordon H, Ralston E, Hall Z, Lupa M, Rotundo R, Bertetta C, Gomez A, Barton F, Randall W (1992) Regulation of molecules at the neuromuscular junction. In: Neuromuscular development and disease (Kelly AM, Blau HM, eds), pp 251-283. New York: Raven.

Shepherd D, Brehm P (1992) Functional properties of acetylcholine receptors in a mouse muscle cell line. Biophys Soc 61:A106.

Siegelbaum S, Trautmann A, Koenig J (1984) Single acetylcholincactivated channel currents in developing muscle cells. Dev Biol 104: 366-379.

Steinbach JH (1989) Structural and functional diversity in vertebrate skeletal muscle nicotinic acetylcholine receptors. Ann Rev Biol 51: 353-365.

Steinbach JH, Zempel J (1987) What does phosphorylation do for the nicotinic acetylcholine receptor? Trends Neurosci 10:61-64.

Yu L, Leonard RJ, Davidson N, Lester HA (1989) Single-channel properties of mouse-Torpedo acetylcholine receptor hybrids expressed in Xenopus oocytes. Mol Brain Res 10:203-211. 